\title{
Developement of Quantitative Analysis of Sparfloxacin by High Performance Liquid Chromatography
}

\author{
Nurun Nahar Rahman and Shahabuddin Ahmad
}

\author{
Department of Pharmaceutical Chemistry, University of Dhaka, Dhaka-1000, Bangladesh
}

\begin{abstract}
An attempt has been made to develop a simple, sensitive and rapid high performance liquid chromatographic (HPLC) method of analysis for sparfloxacin using $35 \%$ acetonitrile in buffer solution as mobile phase. Buffer solution ( $40 \mathrm{mM}$ of sodium dihydrogen phosphate in de-ionized water) was used as solvent to dissolve sparfloxacin and $0.05 \mathrm{mg} / \mathrm{ml}$ stock solution was prepared. Sparfloxacin solution was scanned with UVspectrophotometer and the absorption maximum $\left(\lambda_{\max }\right)$ was found at $292 \mathrm{rim}$. This method was successfully applied to four tablet dosage forms of sparfloxacin encoded as $\alpha, \beta, \delta$, and $\gamma$, from four different companies and the result was found to be satisfactory and reproducible.
\end{abstract}

Key words: Sparfloxacin, HPLC, analysis

\section{INTRODUCTION}

Sparfloxacin is one of the third generation fluoroquinolones with some specific activity in upper respiratory tract infections and community acquired pneumonia. It is an INN drug and as such it has not yet included in the BP or USP. A number of analytical methods ${ }^{1-8}$ have been developed for the analysis of sparfloxacin for research purposes. Of these the most widely used method for the analysis of sparfloxacin is based on HPLC with specific mobile phase composition for a particular condition. Here is an approach demonstrating a simple and rapid HPLC method for the estimation of sparfloxacin in pharmaceutical preparations that can also be used for quantitative estimation .

Correspondence to: Nurun Nahar Rahman Phone: 9661920-79 Ex: 8132

E-mail: nnaharr@univdhaka.edu

Dhaka Univ. J. Pharm. Sci. 6(1): 21-23, 2007 (June)

\section{MATERIALS AND METHODS}

Standard sparfloxacin hydrochloride was a kind gift from Beximco Pharma Ltd. Its declared potency was $99.98 \%$ and was used without further purification. Acetonitirle was of HPLC grade, purchased from Merc, Germany. Sodium dihydrogen phosphate was purchased from Merc, Germany and de-mineralized water was used throughout the experiment. Mobile phase was prepared as 35\% acetonitrile in buffer solution and the $\mathrm{pH}$ was maintained as 2.8. Buffer solution was prepared with sodium dihydrogen phosphate in DM water. HPLC column used was stainless steel column $(25 \mathrm{~cm}$ x 4.6 $\mathrm{mm}$ i.d.) packed with Nucleosil C-18 and average particle size is $5 \mu$.

Standard Preparation. Two hundred $\mathrm{mg}$ of standard sparfloxacin was accurately weighed and taken in a one liter volumetric flask, dissolved and made up to the mark with the mobile phase. Then 5 , $10,15,20$ and $25 \mathrm{ml}$ of aliquots were taken in a series of five separate $100 \mathrm{ml}$ volumetric flasks and 
diluted up to the mark with the mobile phase. Thus a series of standard stock solutions having concentration of $10,20,30,40$ and $50 \mu \mathrm{g} / \mathrm{ml}$ were obtained.

Determination of $\lambda_{\text {max. }}$ From the stock solution (20 $\mu \mathrm{g} / \mathrm{ml})$ approximately $50 \mathrm{ml}$ was taken and scanned from 200 to $400 \mathrm{~nm}$ with Shimadzu Double Beam UV-VIS 160A Spectrophotometer. The mobile phase was used as the blank. Sparfloxacin was found to absorb maximum radiation at $292 \mathrm{~nm}$.

Calibration curve. The series of standard solution prepared above $(10,20,30,40$ and $50 \mu \mathrm{g} / \mathrm{ml})$ were taken and from each solution $10 \mu \mathrm{l}$ was injected into the HPLC column and the peaks were determined at $292 \mathrm{~nm}\left(\lambda_{\max }\right.$. Then the area under the peak versus concentration were plotted (Figure 2).

Assay in the dosage form. Four different marketed sparfloxacin tablet formulations (Coded $\alpha$, $\beta, \gamma$, and $\delta$ ) were selected for analysis. Five tablets in each were weighed, finely powdered and average weight taken. An accurately weighed portion of the powder equivalent to $200 \mathrm{mg}$ of sparfloxacin was transferred to a $1000 \mathrm{ml}$ volumetric flask, dissolved and made up to the mark with the mobile phase. The solution was filtered with milli pore filter paper. 25 $\mathrm{ml}$ of the solution was taken and processed as per the procedure under calibration curve. $10 \mathrm{pl}$ was injected into the HPLC column and chromatogram taken (Figure 1). The potency of the four different marketed sparfloxacin was then determined from the calibration curve (Table 1).

Table 1. Estimation of sparfloxacin in tablets.*

\begin{tabular}{ccc}
\hline $\begin{array}{c}\text { Formulation } \\
\text { code }\end{array}$ & $\begin{array}{c}\text { Amount of } \\
\text { sparfloxacin } \\
\text { claimed (mg/tab) }\end{array}$ & $\begin{array}{c}\text { Amount percent } \\
\text { labeled (Proposed } \\
\text { method) }\end{array}$ \\
\hline$\alpha$ & 200 & $95.82 \%$ \\
$\beta$ & 200 & $94.64 \%$ \\
$\gamma$ & 200 & $96.70 \%$ \\
$\delta$ & 200 & $95.68 \%$ \\
\hline
\end{tabular}

**B.P. limit: $95-105 \%$.** Mean result of three replicates.

Recovery experiment. Powder equivalent to $200 \mathrm{mg}$ of sparfloxacin were taken in five $100 \mathrm{ml}$ volumetric flask and 0, 10, 2030 and $40 \mathrm{mg}$ standard sparfloxacin were added respectively. Then each was diluted with the mobile phase and the potency was determined by the proposed method. The data of the recovery experiment were statistically analyzed to study the reproducibility and validity of the proposed method (Table 2).
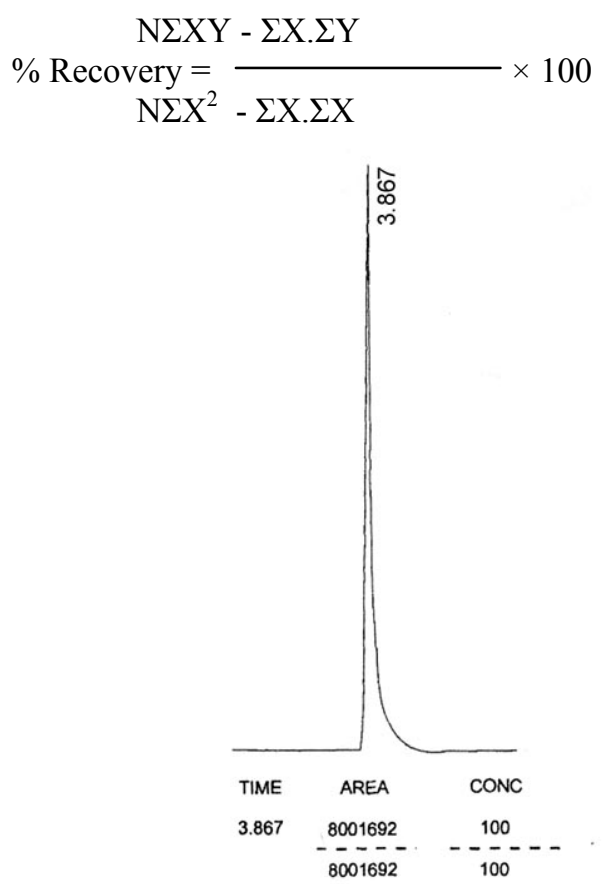

Figure 1. HPLC chromatogram of sparfloxacin.

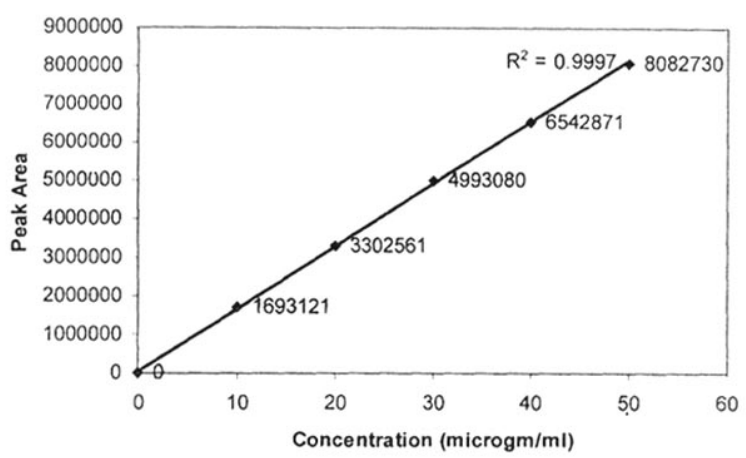

Figure 2. Standard curve of sparfloxacin.

\section{RESULTS AND DISCUSSION}

Sparfloxacin is insoluble in water and methanol, moderately soluble in sodium hydroxide. So sodium dihydrogen phosphate was used as solvent and after long trial and error method 35\% acetonitrile in sodium dihydrogen phosphate buffer $(40 \mathrm{mM})$ was 
established as mobile phase. The proposed method is simple, rapid and handy because the mobile phase is a binary mixture and easy to prepare. It does not require any complex calculation. The standard calibration obtained by plotting known concentrations of sparfloxacin against corresponding area values was found to be linear (Figure 2). Beer's law was found to be obeyed in the concentration range of 10 to $50[\mathrm{ig} / \mathrm{ml}$. The method has been successfully applied for the estimation of sparfloxacin in commercial tablet preparations (coded as $\mathrm{a},(3, \mathrm{y}$ and $\mathrm{S})$, the result of which were represented in Table 1. In order to confirm the reproducibility and validity of the proposed method recovery experiment 9 was conducted. The recovery was almost $100 \%(99.14 \%)$ which showed that the method developed suffered no interference from common excipients used in the formulation. (Table 2) The lower values of standard deviation and coefficient of variation reflect the validity and reproducibility of the proposed method. The values of different statistical parameters indicate that the proposed method is accurate enough to give a valid and accepted result. The calculated $\mathrm{P}$ value was exceedingly low $(\mathrm{P}<0.0001)$ which means that the difference of labeled potency and determined potency by the proposed method is insignificant. The shortest length of confidence interval with $95 \%$ and $99 \%$ indicates the accuracy and validity of the proposed method. The present method thus offers several advantages in terms of simplicity, rapidity and accuracy over many of the known procedures and can be applied for the quality control analysis of sparfloxacin in pharmaceutical preparations.

Table 2. Statistical analysis for recovery experiment of proposed method

\begin{tabular}{|c|c|c|c|c|}
\hline \multirow{2}{*}{$\begin{array}{c}\text { Standrad } \\
\text { addition (mg) } \\
\text { (X) }\end{array}$} & \multirow{2}{*}{$\begin{array}{l}\text { Amount of sparfloxacin } \\
\text { recovered }(\mathrm{mg}) \\
\text { Mean }(\mathrm{Y}) \pm \mathrm{SEM}\end{array}$} & \multirow{2}{*}{$\begin{array}{l}\text { Co-efficient of } \\
\text { Variation (C.V.) }\end{array}$} & \multicolumn{2}{|c|}{ Confidence Interval } \\
\hline & & & $\begin{array}{c}95 \% \text { level of } \\
\text { significance }(\mathrm{mg})\end{array}$ & $\begin{array}{c}99 \% \text { level of } \\
\text { significance }(\mathrm{mg})\end{array}$ \\
\hline 00.0 & $193.40 \pm 0.08165$ & 0.08 & $193.1-193.7$ & $192.9-193.9$ \\
\hline 10.0 & $206.82 \pm 0.1550$ & 0.15 & $206.2-207.2$ & $205.8-207.6$ \\
\hline 20.0 & $215.46 \pm 0.00707$ & 0.01 & $215.4-215.5$ & $215.4-215.5$ \\
\hline 30.0 & $233.12 \pm 0.00408$ & 0.00 & $223.1-223.1$ & $223.1-223.1$ \\
\hline 40.0 & $234.82 \pm 0.004083$ & 0.00 & $234.8-234.8$ & $234.8-234.8$ \\
\hline
\end{tabular}

The percent recovery was calculated by the following equation:

\section{REFERENCES}

1. Ming, Li. DU., Zhe, FengFAN., JinLi,QIAO., Jing Ping, WANG. 2000. Determination of Sparfloxacin in Human Urine by Reversed-phase High Performance Liquid Chromatography with Nitrous Acid and Hydroiodic PreColumn Derivatization. Chinese Chemical Letters. 12(11):1007-1010.

2. Borner, K., Borner, E. and Lode, H. 1992. Determination of sparfloxacin in serum and urine by high-performance liquid chromatography. J. Chromatogr. 579(2): 285-9.

3. Kamberi, M., Kamberi, P., Hajime, N., Uemura, N., Nakamura, K. and Nakano, S. 1999. Determination of sparfloxacin in plasma and urine by a simple and rapid liquid chromatographic method. Ther. Drug Monit. 21(4): 411-5.

4. Lyon, DJ., Cheung, SW., Chan, CY. and Cheng, AF.1994. Rapid HPLC assay of clinafloxacin, fleroxacin, levofloxacin, sparfloxacin and tosufloxacin. J. Antimicrob Chemother. 34(3): 446-8.
5. Wright, DH., Herman, VK., Konstantinides, FN. and Rotschafer, JC. 1998. Determination of quinolone antibiotics in growth media by reversed-phase high-performance liquid chromatography. J. Chromatogr B Biomed Sci Appl. 709(1): 97-104.

6. Marona, H. R. N., Zuanazzib, J.A.S. and Schapoval, E.E.S. 1999. Determination of sparfloxacin and its degradation products by HPLC-PDA. J. Antimicrob Chemother. 44: 301302.

7. Marona, H.R.N. and Schapoval, E.E.S. 1999. A highperformance liquid chromatographic assay for sparfloxacin, J. Pharmaceutical and Biomedical Analysis 20(3): 413417.

8. Marona, H.R.N. and Schapoval, E.E.S. 2001, Spectrophotometric determination of sparfloxacin in pharmaceutical formulations using bromothymol blue, $J$. Pharmaceutical and Biomedical Analysis 26 (3): 501-504.

9. Paul, T.K., Bachar, S.C., Rebecca Banoo, Farida Begum and Datta, B.K.2002 Colorimetric Determination of Paracetamol from Pharmaceutical Dosage Form. Dhaka Univ. J. Pharm. Sci. 1(1-2): 31-34. 
